\title{
XXV. A new spectrophotometer of the Hüfner type
}

\section{Robert A. Houstoun Ph.D. D.Sc.}

To cite this article: Robert A. Houstoun Ph.D. D.Sc. (1908) XXV. A new spectrophotometer of the Hüfner type , Philosophical Magazine Series 6, 15:86, 282-287, DOI:

10.1080/14786440809463768

To link to this article: http://dx.doi.org/10.1080/14786440809463768

\section{Published online: 16 Apr 2009.}

Submit your article to this journal

Џلl Article views: 2

Q View related articles ¿ 
atomic weight of 232 , and an approximate specific gravity of $7^{*}$.

Assuming this hypothetical member to be radium, the combining equivalent of its chloride with silver ( $\mathrm{Cl} 35$ and Ag 108) would be 1.399 in accordance with the determinations arrived at with the other members of the same series, and not 1.371 as determined experimentally for the intermediate atomic weight 226 , recently assigned to radium $\dagger$.

XXV. A New Spectrophotometer of the Hüfner Type. By Robert A. Houstoun, Ph.D., D.Se., Assistant to the Professor of Natural Philosophy in the University of Glasgow $\ddagger$.

DURING the past forty years a great number of different 1 spectrophotometers have been worked out. This will readily be seen by a reference to Kayser's Spectroscopie, vol. iii. chap. 1, where a complete list is given $\S$. But although so much attention has been given to designing and testing new instruments, few spectrophotometers have been made, and most laboratories are without one. This must in part be ascribed to their cost, and also to their construction, which usually prevents them from being used for any other purpose. The object of the present paper is to describe an attachment which may be fitted to any spectrometer or spectroscope, converting it into a spectrophotometer, and which may be removed at once when the ordinary use of the instrument is desired. A method for applying the instrument to the measurement of absorption in the ultra-violet is also described.

Fig. 1.

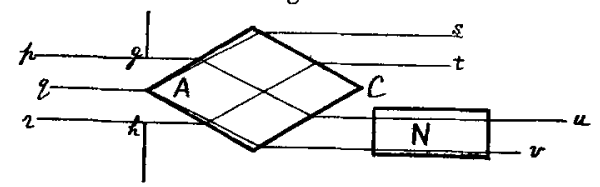

The Hüfner Spectrophotometerll consists (fig. 1) of a spectroscope, before the slit of which a Glan-Thompson prism

* Manchester Memoirs, vol. li. No. 2 (1906).

+ Comptes Rendus, vol. cxlv. p. 422 (1907).

$\ddagger$ Communicated by Professor A. Gray, F.R.S.

$\S$ This list does not mention the new form of the König spectrophotometer designed by Dr. Martens ("Ueber eine Neukonstruktion des Königsehen Spektralphotometers," F. F. Martens u. F. Grunbaum, Ann. der Phys. xii. p. 984, 1903), and the spectrophotometer of Dr. J. Milne ('Nature,' lxxii. p. 391, 1905).

II "Ueber ein neues Spectrophotometer" von G. Hüfner, Zs. f. physsc. Chemie, iii. pp. 562-571 (1889). 
$\mathrm{N}$ and a glass rhomb AC-the Hüfner rhomb-is brought. The edge $\mathrm{A}$ is ground very sharp and bisects the slit $g h$. If we disregard the polarizing effect of the rhomb, the upper beam bounded by the rays $s \mathrm{~A} q$ and $t h r$, which illuminates the lower half of the slit, consists of natural light, and the beam bounded by the rays $u g p, v \mathrm{~A} q$, which illuminates the upper balf of the slit, consists of light polarized in either a vertical or horizontal plane. Another nicol is inserted in the path of both beams. If we look into the eyepiece, we see two spectra, one above the other, and by rotating this nicol we can alter their relative intensity.

The light which comes from the upper half of the slit must be plane-polarized before entering the second nicol, and the light which comes from the lower half of the slit must be unpolarized natural light. But it is partially polarized by both the Hüfner rhomb and dispersion-prism. Hüfner was perfectly aware of this, and in his improved instrument made by Albrecht he got over the difficulty by choosing the glass and angle of the dispersion-prism so that it removed the polarization produced by the rhomb ( $c f$. article cited, 1. 564). Messrs. Hilger have apparently rediscovered the same method of removing the polarization produced by the rhomb, and it is described at length by Mr. F. Twyman* under the impression that it is new.

Any dispersion-prism will not do then. Its angle must be chosen so as to remove the polarization produced by the rhomb.

I have recently designed a prism which performs the functions of both the rhomb $\mathrm{AC}$ and the Glan-Thompson prism $\mathrm{N}$, but which polarizes both beams in planes at right angles to one another, and thus can be used with any dispersion-prism whatever (fig. 2).

Fig. 2.

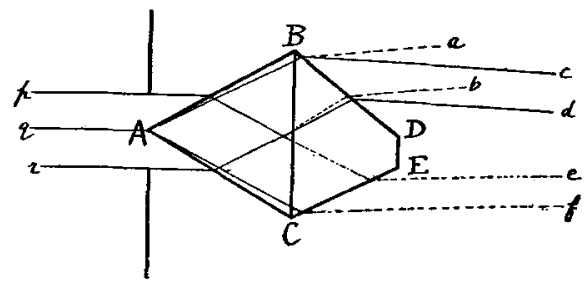

$\mathrm{ABC}$ is made of glass $\mu_{\mathrm{D}}=1.526$, the sides $\mathrm{AB}, \mathrm{BC}, \mathrm{CA}$

* "Improvements in the Hüfner type of Spectrophotometer." F. Twyman, Phil. Mag. April 1907. 
being each $2 \mathrm{cms}$. long. It is cemented to a prism of Iceland spar, BDEC, cut with its axis perpendicular to the plane of the paper. The angle $\mathrm{D}$ is $127^{\circ} 12^{\prime}, \mathrm{E}$ is $115^{\circ} 49^{\prime}$, and $\mathrm{BCE}$ is $36^{\circ} 44^{\prime}$.

The action of the prism may be better understood by considering the beams of light to go in the reverse direction -from the object-glass of the collimator to the slit. The beam $q r$ is broken into two by the Iceland spar prism, $c d$ being the ordinary beam and $a b$ the extraordinary. The beam $p q$ is broken into two, but only the extraordinary ef emerges, the ordinary being totally reflected at the surface CE. The beams $e f, c d$ meet $15 \mathrm{cms}$. out in an elliptical spot of light measuring $2 \cdot 0$ by $2 \cdot 4 \mathrm{cms}$., the long axis being vertical. The beam $a b$ is quite $2 \mathrm{cms}$. clear.

If now we have as source of light an incandescent mantle behind a screen, with an aperture at the proper place not much larger than 2.0 by $2.4 \mathrm{cms}$., and if we look into the eyepiece, we see two spectra one above the other and polarized at right angles to one another. The ordinary component of the Jower beam misses the slit entirely, the extraordinary component of the upper beam misses the object-glass of the collimator.

The prism was fixed in a rectangular brass cell open at the ends with the edge $A$ protruding. The brass cell was mounted in a short piece of brass tubing with a milled head, which turned inside another piece of brass tubing fixed in front of the slit. The prism could thus be rotated about the axis of the collimator-the only adjustment necessary. The inner tube containing the cell could be removed when required, the outer tube remaining fixed to the slit. When it was returned to its plane the milled head prevented it sliding in too far and damaging the edge $A$. The prism was attached to one of W. Wilson's well-known College spectrometers.

All that is then required to complete the equipment of the instrument as a spectrophotometer is one of the nicol-prism polarizers with a divided circle, which is supplied by the makers to fit over the object end of the collimator. This is preferable to the object end of the telescope as it avoids the depolarizing effect of the dispersion-prism. The eyepiece supplied with the instrument for ordinary use magnifies, however, too strongly, when it is used as a spectrophotometer.

Much the better place for the nicol, however, is the eyepiece. In spectrophotometry it is necessary to waste as little light as possible. The object-glasses of collimator and telescope had a clear aperture of one inch. A nicol with an aperture of one inch would be too expensive, and makers 
usually fit a much smaller nicol, thas causing a large loss of light. In the eyepiece the rays come closer together, and a smaller nicol may be used. An ocular nicol with divided circle, reading telescope, and screens for cutting out the regions of the spectrum not under observation was therefore made by F. Schmidt and Haensch, Berlin, to replace the ordinary eyepiece. The prism for attaching to the slit was made by $R$. \& J. Beck, Ltd. Its angles do not require to be made accurately, the only point necessary being that the axis of the Iceland spar should be parallel to the edge A. It is extremely important that the slit prism be set with the axis of the Iceland spar perpendicular to the refracting edge of the dispersion-prism. If that is not the case, the two beams are not polarized in and perpendicular to the plane of incidence when they enter the dispersion-prism. Their planes of polarization will then be rotated, and the positions in which the ocular nicol extinguishes the upper and lower spectra will not be at right angles to one another. The correct position of the slit prism may thus be found by trial.

If it is preferred to keep the one beam unpolarized, as in the ordinary Hüfner spectrophotometer, then a prism of the form shown in fig. 3 might be used. $A B C$ and $B F D$ are

Fig. 3.

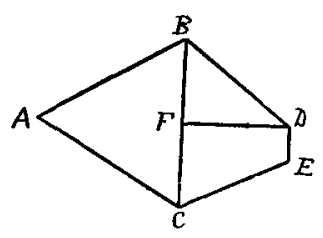

glass, FDEC is Iceland spar. There is now no light lost by reflexion in the nicol. Owing to the space saved, wider cells might be used and the absorption of more dilute solutions measured.

The limitation of the size of the aperture causes no difficulty in practice.

With reference to the accuracy obtained, it is not possible with a Hüfner rhomb to get the two spectra under comparison to touch one another so sharply as in the case of a LummerBrodhun cube or a biprism such as is used in the Koenig-Martens spectrophotometer, as my experience of the Phil. Mag. S. 6. Vol. 15. No. 86. Feb. 1908. 
latter instrument has shown me*. The latter instrument also has the advantage that the polarizing prism is placed after the dispersion-prism and the error due to depolarized light removed. In practice, however, since twice as much light is lost in the latter instrument, the Hüfner spectrophotometer is as accurate, and is of course simpler. The University of Glasgow possesses a Wild spectrophotometer, but so much light is lost in the latter instrument that in accuracy it is very much inferior to the others.

To test the possibilities of the instrument for spectrophotometry in the ultra-violet, I attempted to measure the absorption of copper sulphate photographically. Copper sulphate was chosen because it is a salt for which accurate values are given in Landolt and Börnstein's tables. It absorbs the red end of the spectrum, but the results show that rough quantitative work in the ultra-violet could be done very easily.

A nicol was attached to the end of the collimator. The diameter of its aperture was less than one quarter the diameter of the lens, and hence there was a great loss of light. In place of the telescope there was placed a camera, the focal length of its lens being about $51 \mathrm{cms}$. Wratten and Wainwright's panchromatic plates were used. The spectrum from 6700 to 3500 , where the absorption of the glass begins, was taken at one exposure and measured more than $5 \mathrm{cms}$. in length.

First of all both beams were left free and the nicol set so that its plane of polarization made angles of $55^{\circ}, 52^{\circ}$, and $50^{\circ}$ with the plane of polarization of the lower beam. At $52^{\circ}$ the one spectrum was brighter, at $50^{\circ}$ the other, so $51^{\circ}$ was taken to be the angle at which the nicol would be set for equal brightness. A photograph was then taken of the flame spectrum of $\mathrm{Li}, \mathrm{K}, \mathrm{Na}$, and $\mathrm{Th}$, and the wave-length of a point of the plate determined in terms of its distance from the $D^{\circ}$ lines.

Then the cell with the copper sulphate was placed in position, and exposures made for different positions of the nicol. A bunsen flame with a sodium bead was placed between the incandescent mantle and the cell. The sodium line appeared therefore on all the plates. The distance of the point on the plate where the two spectra touching one another were equally black was measured from the D line, and the wave-length of the point could thus be determined.

* "Untersuchungen über die Absorption des Lichtes in isotropen Körpern," R. A. Houstoun, Ann. der Physik, xxi. p. 535 (1906). 
If $a$ gives the position of the nicol, the fraction of the intensity of the incident beam transmitted by the solution is given by

$$
\mathrm{I}=\mathrm{I}_{0} \frac{\tan ^{2} \alpha}{\tan ^{2} 51^{\circ}} .
$$

If $c$ denote the concentration of the solution in grammolecules per litre, and $d$ the thickness of solution passed through, then A the "molecular extinction coefficient" is defined by

$$
\mathrm{I}=\mathrm{I}_{0} 10^{-\mathrm{Acd}} \text {. }
$$

The following table gives the results :-

\begin{tabular}{|c|c|c|c|c|}
\hline$\alpha$. & $\begin{array}{c}\text { Time of } \\
\text { exposure. }\end{array}$ & $\lambda$. & $\Delta$. & $\begin{array}{c}\text { A from the } \\
\text { tables. }\end{array}$ \\
\hline $49 \cdot 8$ & 10 mins. & 4750 & 0.053 & 0.009 \\
$47 \cdot 4$ & $"$ & 5640 & $0 \cdot 187$ & $0 \cdot 29$ \\
45.0 & $"$ & 5710 & 0.322 & 0.37 \\
41.6 & $"$ & 5850 & 0.514 & 0.57 \\
38.1 & $"$ & 5980 & 0.714 & 0.83 \\
30.0 & 15 mins. & 6130 & $1 \cdot 22$ & 1.24 \\
23.1 & 20 mins. & 6200 & 1.69 & $1 \cdot 50$ \\
14.9 & $"$ & 6410 & $2 \cdot 45$ & $2 \cdot 42$ \\
\hline
\end{tabular}

$c=0.5424 \mathrm{gm} .-$ molecules/litre.

$d=1 \mathrm{~cm}$.

The width of the $\mathrm{D}$ line on the plates is $0.6 \mathrm{~mm}$.

One exposure gives A for only one wave-length, but if the absorption had more than one maximum the exposure might give $A$ for several values of $\lambda$. The values of $A$ taken from the tables are of course more accurate. I attempted to determine the wave-length by putting a piece of didymium glass before the slit, but this method was not so accurate as the one used.

The cost of the instrument has been borne by the Carnegie Trust for the Universities of Scotland. 